\title{
Novel Carrier based PWM Techniques Reduce Common Mode Voltage for Six Phase Induction Motor Drives
}

\author{
Ngoc Thuy Pham ${ }^{1}$ \\ Dept. of ET, Industrial University of Ho Chi Minh \\ Ho Chi Minh City, Viet Nam
}

\author{
Nho Van Nguyen ${ }^{2}$ \\ Dept. of EEE, Ho Chi Minh University of Technology \\ Ho Chi Minh City, Viet Nam
}

\begin{abstract}
This paper proposes a novel pulse width modulation (CBPWM) technique for reducing the common mode voltage for a six-phase induction motor (SPIM) drive. This proposed CBPWM technique relies on setting up offset functions and the phase shift of carrier wares. Common mode voltage occurs under the effect of DC power Vd always in $\mathrm{Vd} / 6$ limits. Some ways of designing the offset function are proposed; these proposed strategies permit to reduce either the mean value or the instantaneous value of the common mode voltage. Features of proposal CBPWM solutions have been compared. Simulation and experimental results demonstrate the feasibility of the proposed solution.
\end{abstract}

Keywords-Six-phase induction motor; six-phase voltage source inverter; common mode voltage; carrier based pulse width modulation

\section{INTRODUCTION}

In recent decades, multi-phase motors have become increasingly popular, especially in medium to large power applications such as automotive, aerospace, military and nuclear [1,2]. The use of multi-phase drives has been considered an effective approach to achieving high power without increasing the stator currents per phase. Among the numerous possibilities of multiphase ac machines, SPIM is probably the most popular in industrial applications. Nowadays, SPIM are even considered for small power in all applications requiring reliability and fault tolerance [3], [4]. In this way, it is expected that the loss of one or more phases allows the machine to provide a significant electromagnetic torque to run the system. On the other hand, the high performance of modern power converters in terms of switching frequency and control capability can be used to reduce torque oscillations in the case of phase loss [5]. In the SPIM drive, the use of a six-phase inverter (6P_VSI) as a necessary choice because in fact, the six-phase power supply is not available. As we all know, in order to control 6P_VSI, different pulse width modulation (PWM) techniques are employed to achieve the voltage quality criterion. The classic PWM techniques such as space vector modulation (SVPWM), continuous carrier modulation (CPWM) technique, and the sine modulation (SINPWM) technique is commonly used to generate the good voltage quality, voltage distortion caused by harmonics is low. Discontinuous modulation (DPWM) techniques have also been developed, which allows reducing the switching losses, higher tolerance distortion. However, the above PWM modulation methods cause high common mode pulse. This common mode voltage generates the parasitic current components that appear between the metal part of the stator and the rotor, between the stator and the housing. As a consequence of this common mode voltage effect, electromagnetic interference (EMI) current appears to corrode the bearing surface of the motor, on the other hand, EMI current with the interference activation of protective devices and heating the wires [6-9]. Thus, the application of six-phase inverter does not completely satisfy the high- quality requirements of practical electric drives, especially when DC power is high [6], [7], [9]. The goal of the inverter voltage control is to suppress the negative influence caused by common mode voltage. Some practical solutions use serial reactor with the inverter output or use a hardware circuitry contain semiconductor switch to control common mode voltage compensation [10,11]. However, techniques use expensive hardware circuits and even reduce system reliability. Thus, the current trend is more concerned with PWM techniques that use the space vector and carrier based on techniques that reduce or eliminate the common mode voltage [12]. Although the SPIM drive has been studied for a quite long time, common research results for common-mode voltage reduction are less well known than the common mode reduction of three-phase induction motor drive [9], [13, 14]. One of the few common uses of PWM technology is the reduction of common mode for symmetric six phase inverters or 5-phase inverters [1], [15-16]. The 6P_VSI is capable of controlling the common mode voltage reduction/elimination because the space vector schema contains a number of zero common-mode voltages. Compared with space vector PWM technique, carrier based on PWM techniques have available some conveniences as less calculating, apply in cases extending PWM techniques for power conversion systems easily such as three phase multilevel inverters, or multiphase inverter. For that purpose, the paper proposes a common mode voltage reduction technique using CBPWM methods, called RCMV CBPWM (Reduced Common Mode Voltage CBPWM). The phenomenon of switching simultaneously at two inverter branches also leads to a large change in $\mathrm{dv} / \mathrm{dt}$ between phases. Hence, it creates a load current has large noise peak and causes leakage currents through parasitic capacitors between phases in the cables. On the other hand, the PWM techniques suppress the CMV have limited range of output voltage. Therefore, another possible solution is researched to reduce $\mathrm{CMV}$. 
The paper presented the new CBPWM technique for controlling voltage reduction common mode for six phase inverter. The simple implementation method by applying offset function combinate with carrier technique in six phase control voltage. These $4 \mathrm{~S}-\mathrm{CBPWM}$ techniques control and reduce the common mode voltage amplitude in the range $\mathrm{Vd} / 6$. Compared to the space vector modulation techniques, the carrier based PWM modulation technique are less computation, easy to apply when expanding PWM technology for power conversion systems such as multi-level inverter or multi-phase inverter.

In this paper, the new CBPWM techniques are presented for controlling and reducing the common mode voltage for six phase inverter. The methods implemented by applying offset function combine with carrier technique. These 4S-CBPWM techniques control and reduce the common mode voltage amplitude in the range $\mathrm{Vd} / 6$. Compared to the space vector modulation techniques, the carrier based PWM modulation technique are less computation, easy to apply when expanding PWM technology for power conversion systems such as multilevel inverter or multi-phase inverter. The achieved simulation and experiment results demonstrate the effectiveness of the proposed CBPWM RCMV techniques.

This paper is organized into five sections. In section 2, the basic theory of the model of SPIM drive and SPIM are presented. Section 3 introduces the principle of proposed RCMV CBPWM. Simulation and experiment results are presented in Sections 4 and 5. Finally, the concluding is provided in Section 5

\section{MODEL OF SPIM DRIVE AND SPIM}

The system under study consists of SPIM fed by a sixphase VSI (Voltage Source Inverter) and a DC link. A detailed scheme of the drive is provided in Fig. 1. This SPIM is a continuous system that can be described by a set of differential equations. The model of the system can be simplified by means of the vector space decomposition (VSD). By applying this technique, the original six-dimensional space of the machine is transformed into three two-dimensional orthogonal subspaces in the stationary reference frame $(\alpha-\beta),(x-y)$ and (zl $-\mathrm{z} 2$ ). This transformation is obtained by means of $6 \times 6$ transformation matrix:

$\mathrm{T}_{6}=\frac{1}{3}\left[\begin{array}{cccccc}1 & \cos \gamma & -\frac{1}{2} & \cos \left(\frac{2 \pi}{3}+\gamma\right) & -\frac{1}{2} & \cos \left(\frac{4 \pi}{3}+\gamma\right) \\ 0 & \sin \gamma & \frac{\sqrt{3}}{2} & \sin \left(\frac{2 \pi}{3}+\gamma\right) & -\frac{\sqrt{3}}{2} & \sin \left(\frac{4 \pi}{3}+\gamma\right) \\ 1 & \cos (\pi-\gamma) & -\frac{1}{2} & \cos \left(\frac{\pi}{3}-\gamma\right) & -\frac{1}{2} & \cos \left(\frac{5 \pi}{3}-\gamma\right) \\ 0 & \sin (\pi-\gamma) & -\frac{\sqrt{3}}{2} & \sin \left(\frac{\pi}{3}-\gamma\right) & \frac{\sqrt{3}}{2} & \sin \left(\frac{5 \pi}{3}-\gamma\right) \\ 1 & 0 & 1 & 0 & 1 & 0 \\ 0 & 1 & 0 & 1 & 0 & 1\end{array}\right]$

In that, an amplitude invariant criterion was used. From the motor model obtained by using the VSD approach, the following conclusions should be emphasized:

- The electromechanical energy conversion variables are mapped to the $(\alpha-\beta)$ subspace. Therefore, the fundamental supply component as well as the supply harmonics of order $12 n \pm 1(n=1,2,3, \ldots)$, are represented in this subspace. The nonelectromechanical energy conversion variables can be found in other subspaces.

- The current components in the (x-y) subspace do not contribute to the air gap flux and are limited only by the stator resistance and stator leakage inductance, which are usually small. These components represent the supply harmonics of the order $6 n \pm 1(n=1,3,5, \ldots)$ and only produce losses, so consequently they should be controlled to be as small as possible.

- The voltage vectors in the (zl -z2) are zero due to the separated neutrals configuration of the machine.

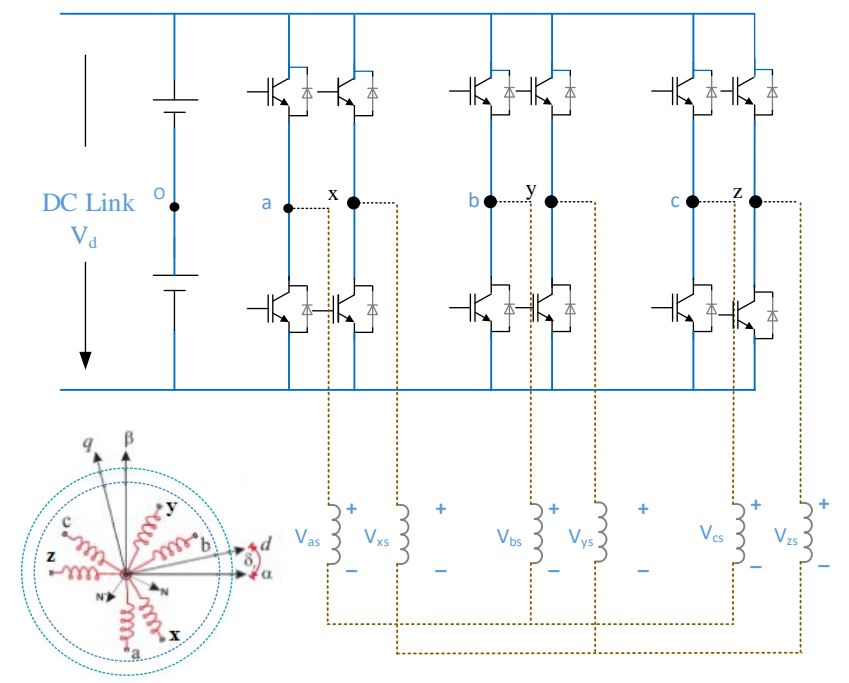

Fig 1. A general scheme of SPIM drive.

A 3P_VSI has a discrete nature, actually, it has a total number of $2^{6}=64$ different switching states defined by six switching functions corresponding to the six inverter legs [Sa, Sx, Sb, Sy, Sc, Sz], where Si $€\{0,1\}$. The different switching states and the voltage of the DC link define the phase voltages which can turn be mapped to the $(\alpha-\beta)$ - $(x-y)$ space according to the Vector space decomposition VSD approach. For this reason, the 64 different on/off combinations of the six legs of VSI lead to 64 space vectors in the $(\alpha-\beta)$ and $(x-y)$ subspaces. Fig. 2 shows the active vectors in the $(\alpha-\beta)$ and $(x-y)$ subspaces, where each vector switching state is identified using the switching function by two octal numbers corresponding to the binary numbers [SaSbSc] and [SxSySz], respectively.
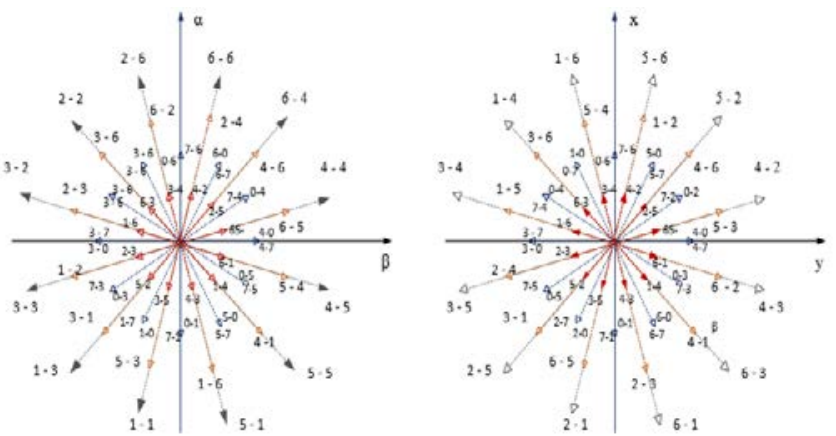

Fig 2. Voltage space vectors and switching states in the $(\alpha-\beta)$ and (x-y) subspaces for a six-phase asymmetrical VSI. 
Fig. 2 the 64 possibilities lead to only 49 different vectors in the $(\alpha-\beta)-(x-y)$ subspace. On the other hand, a transformation matrix must be used to represent the stationary reference frame $(\alpha-\beta)$ in the dynamic reference $(d-q)$. This matrix is given:

$\mathrm{T}_{\mathrm{dq}}=\left[\begin{array}{cc}\cos \left(\delta_{\mathrm{r}}\right) & -\sin \left(\delta_{\mathrm{r}}\right) \\ \sin \left(\delta_{\mathrm{r}}\right) & \cos \left(\delta_{\mathrm{r}}\right)\end{array}\right]$

Where $\delta$ is the rotor angular position referred to the stator as shown in Fig. 1.

A SPIM which contains two sets of three-phase winding spatially are shifted 30 electrical degrees with isolated neutral points or double neutral point, as depicted in Fig. 3, is modeled. Stator and rotor voltage equation for this model is as follows:

$\left[\mathrm{V}_{\mathrm{s}}\right]=\left[\mathrm{R}_{\mathrm{s}}\right]\left[\mathrm{I}_{\mathrm{s}}\right]+\mathrm{P}\left(\left[\mathrm{L}_{\mathrm{s}}\right]\left[\mathrm{I}_{\mathrm{s}}\right]+[\mathrm{M}]\left[\mathrm{I}_{\mathrm{r}}\right]\right)$

$\left[\mathrm{V}_{\mathrm{r}}\right]=\left[\mathrm{R}_{\mathrm{r}}\right]\left[\mathrm{I}_{\mathrm{r}}\right]+\mathrm{P}\left(\left[\mathrm{L}_{\mathrm{r}}\right]\left[\mathrm{I}_{\mathrm{r}}\right]+[\mathrm{M}]\left[\mathrm{I}_{\mathrm{s}}\right]\right)$

Where: [V], [I], [R], $[\mathrm{L}]$ and $[\mathrm{M}]$ are voltage, current, resistant, self, and mutual inductance vectors, respectively. $\mathrm{P}$ is a differential operand. Subscript $\mathrm{r}$, s related to the rotor and stator vectors respectively. Since the rotor is squirrel cage, $[\mathrm{Vr}]$ is equal to zero.

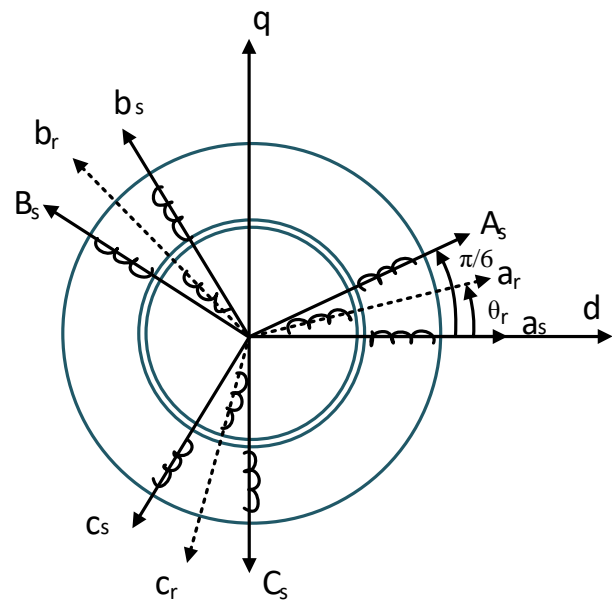

Fig 3. Distribution of coils in six-phase motors.

Applying the transformation matrix [T6], where $\gamma=\pi / 6$, the six-phase motor can be represented in three twodimensional space coordinates: (D-Q), ( $\mathrm{x}, \mathrm{y})$ and ( $\mathrm{z} 1, \mathrm{z} 2)$ :

(D-Q) subspaces :

$\left[\begin{array}{c}V_{s D} \\ V_{s Q} \\ 0 \\ 0\end{array}\right]=\left[\begin{array}{cccc}R_{s}+P L_{s} & 0 & P M & 0 \\ 0 & R_{s}+P L_{s} & 0 & P M \\ P M & \omega_{r} M & R_{r}+P L_{r} & \omega_{r} L_{r} \\ -\omega_{r} M & P M & -\omega_{r} L_{r} & R_{r}+P L_{r}\end{array}\right]\left[\begin{array}{l}I_{s D} \\ I_{s Q} \\ I_{r D} \\ I_{r Q}\end{array}\right]$

(x,y) subspaces :

$\left[\begin{array}{c}V_{s x} \\ V_{s y} \\ 0 \\ 0\end{array}\right]=\left[\begin{array}{cccc}R_{s}+P L_{s} & 0 & 0 & 0 \\ 0 & R_{s}+P L_{s} & 0 & 0 \\ 0 & 0 & R_{r}+P L_{r} & 0 \\ 0 & 0 & 0 & R_{r}+P L_{r}\end{array}\right]\left[\begin{array}{c}I_{s x} \\ I_{s y} \\ I_{r x} \\ I_{r y}\end{array}\right]$

(z1,z2) subspaces:

where: Ls=Lls $+\mathrm{M}, \mathrm{Lr}=\mathrm{Llr}+\mathrm{M}, \mathrm{M}=3 . \mathrm{Lms}, \mathrm{P}=\mathrm{d} / \mathrm{dt}$. As these equations imply, the electromechanical conversion only takes place in the $\alpha-\beta$ subspace (DQ subspace) and the other subspaces just produce losses.

The torque equation can be written as follows:

$T_{e}=3 P\left(\Psi_{\beta r} i_{\alpha r}-\Psi_{\alpha r} i_{\beta r}\right)$

$J_{i} \frac{d}{d t} \omega_{r}+B_{i} \omega_{r}=P\left(T_{e}-T_{L}\right)$

where $\mathrm{Ji}, \omega r, \mathrm{Bi}, \mathrm{Tm}, \mathrm{TL}, \mathrm{P}$ : are inertia coefficient, angular speed, friction factor, the electromagnetic torque that generated by the motor, load torque, number of poles and stator flux linkage at the related subspace.

\section{PRINCIPLE OF RCMV PWM}

\section{A. CBPWM Technique for 6P_VSI:}

1) SVPWM Technique for 6P_VSI: Fig. 4 describes the principle of implementing SVPWM for 6P_VSI. A 6P_VSI contains two the three phase VSI (3P_VSI I and 3P_VSI II) and they are independently PWM controlled. The reference voltage vector is carried out in SVPWM of 3P_ VSI I, which generates the control pulse ( $S_{a} S_{b} S_{c}$ ), is shifted by 30 degrees compared to the reference voltage vector of VSI II. This reference voltage vector is carried out SVPWM of 3P VSI II generate the control pulse $\left(S_{A} S_{B} S_{C}\right)$.

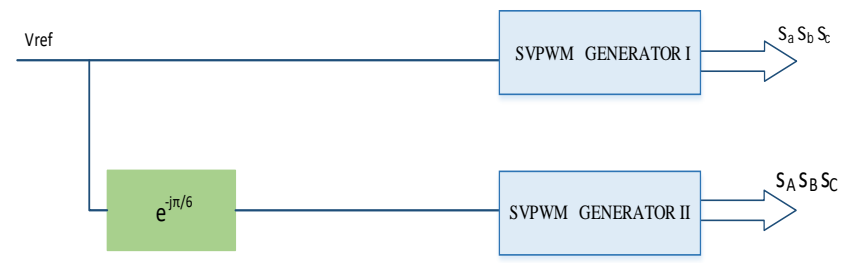

Fig 4. SVPWM technique for SPIM drive.

2) CBPWM Technique for 6P_VSI: Fig. 5 describes the principle of implementing CBPWM for 6P_VSI. Typically, each 3P_VSI I and II can be independently controlled PWM. The control voltage signal of 3P_VSI I is generated by synthesizing the three-phase basic voltage and the offset voltage, This is then compared to the carrier carried out in the CBPWM I block (Fig. 6$)$ that generated the control pulse ( $\mathrm{s}_{\mathrm{a}}$, $\mathrm{s}_{\mathrm{b}}, \mathrm{s}_{\mathrm{c}}$ ).

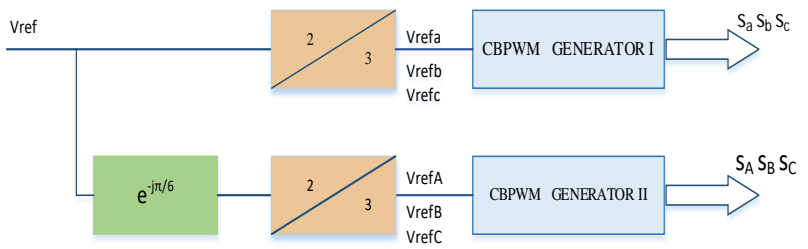

Fig 5. CBPWM technique for SPIM drive. 


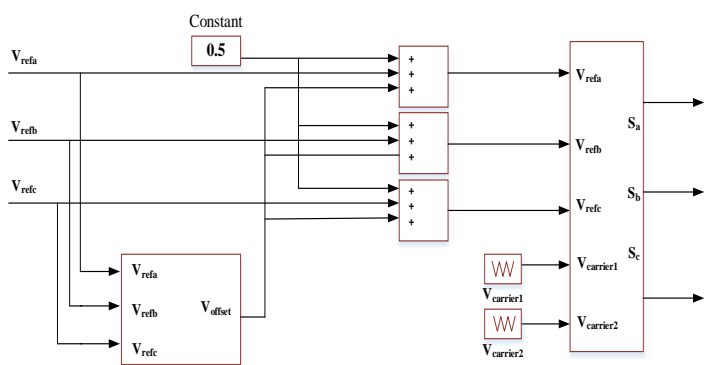

Fig 6. Detail CBPWM block for 3P_VSI I.

Similarly, the basic control voltage signal of 3P_VSI II has a phase angle shift 30 degrees compared to VSI I, This voltage compared to the carrier carried out in the CBPWM II block that generated the control pulses for three phase VSI II $\left(\mathrm{s}_{\mathrm{A}}, \mathrm{s}_{\mathrm{B}}, \mathrm{s}_{\mathrm{C}}\right)$.

The CB PWM block generates the excitation pulse ${ }^{S_{a} S_{b} S_{c}}$ by comparing the control voltage $v_{d k a}, v_{d k b}, v_{d k c}$ to the carrier waves $\mathrm{V}$ carrier. The relationships are described by:

$v_{d k a} V_{d}=V_{\text {refa }}+V_{\text {comI }}+\frac{V_{d}}{2}$

$v_{d k b} V_{d}=V_{r e f b}+V_{c o m I}+\frac{V_{d}}{2}$

$v_{d k c} V_{d}=V_{\text {refc }}+V_{\text {comI }}+\frac{V_{d}}{2}$

Similar, we also can set-up relationship between the control functions for 3P_VSI II:

$v_{d k A} V_{d}=V_{\text {refA }}+V_{\text {comII }}+\frac{V_{d}}{2}$

$v_{d k B} V_{d}=V_{r e f B}+V_{c o m I I}+\frac{V_{d}}{2}$

$v_{d k C} V_{d}=V_{\text {refC }}+V_{\text {comII }}+\frac{V_{d}}{2}$

The reference voltage for the phases of VSI I and II are described as follows:

$V_{\text {refa }}=V_{m} \cos \theta$

$V_{r e f b}=V_{m} \cos \left(\theta-\frac{2 \pi}{3}\right)$

$V_{\text {refc }}=V_{m} \cos \left(\theta-\frac{4 \pi}{3}\right)$

$V_{\text {refA }}=V_{m} \cos \left(q-\frac{p}{6}\right)$

$V_{\text {refB }}=V_{m} \cos \left(q-\frac{2 p}{3}-\frac{p}{6}\right)$

$V_{\text {refC }}=V_{m} \cos \left(q-\frac{4 p}{3}-\frac{p}{6}\right)$

The configuration of 6P_VSI is not symmetrical with two neutral points of two 3P_VSI I and II isolation. The voltage of phase a, b, c called sequentially $v_{a 0}, v_{b 0}, v_{c 0}$ and $v_{A 0}, v_{B 0}, v_{C 0}$. $V_{\text {comI }}$ and $V_{\text {comII }}$ are common mode voltage of 3P_VSI I and II. Calling the switching status sequentially: ${ }^{s_{a}} s_{b} s_{c}$ and Vcom for 6P_VSI is defined:

$$
\begin{aligned}
& v_{\text {comI }}=\frac{v_{a 0}+v_{b 0}+v_{c 0}}{3}-\frac{V_{d}}{2} \\
& v_{\text {comII }}=\frac{v_{A 0}+v_{B 0}+v_{C 0}}{3}-\frac{V_{d}}{2}
\end{aligned}
$$

Assuming that the three-phase stator coils are arranged symmetrically, the common mode voltage can be calculated as follows [1]:

$$
\begin{aligned}
v_{\text {com }} & =\frac{v_{c o m I}+v_{c o m I I}}{2} \\
v_{c o m} & =\frac{v_{a 0}+v_{b 0}+v_{c 0}+v_{A 0}+v_{B 0}+v_{C 0}}{6}-\frac{V_{d}}{2}
\end{aligned}
$$

Description of common mode voltage to the switching states of the semiconductor switch, we have:

$$
\begin{aligned}
& v_{\text {comI }}=\left(\frac{s_{a}+s_{b}+s_{c}}{3}-\frac{1}{2}\right) V_{d} \\
& v_{\text {comII }}=\left(\frac{s_{A}+s_{B}+s_{C}}{3}-\frac{1}{2}\right) V_{d} \\
& v_{\text {com }}=\left(\frac{s_{a}+s_{b}+s_{c}+s_{A}+s_{B}+s_{C}}{6}-\frac{1}{2}\right) V_{d}
\end{aligned}
$$

In order to reduce Vcom, the switching state of the switch are designed to Vcom reaches the smallest values. One of the possibilities, that is each of the 3P_VSI I and II will be controlled independently to minimize Vcom.

\section{B. RCMV 4S-PWM Technique for 6P_VSI:}

1) RCMV 4S-SVPWM technique: A 6P_VSI contains two the three phase VSI (3P_VSI I and 3P_VSI II) and they are independently PWM controlled. To analyze RCMV 4SSVPWM technique we have used a $3 P$ _ VSI scheme as Fig. 7. Vcom can be defined as follows (see Fig. 7).

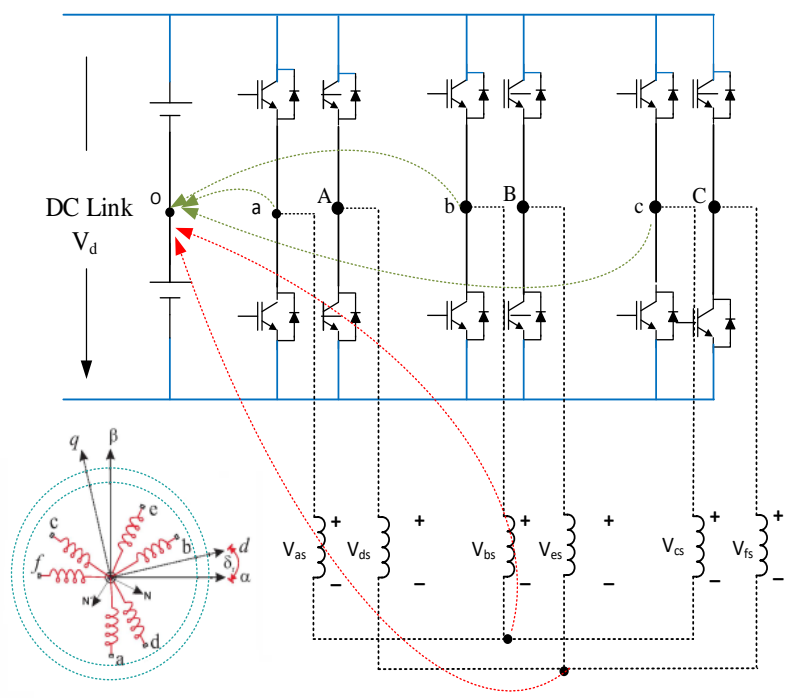

Fig 7. Diagram 3_VSI model 


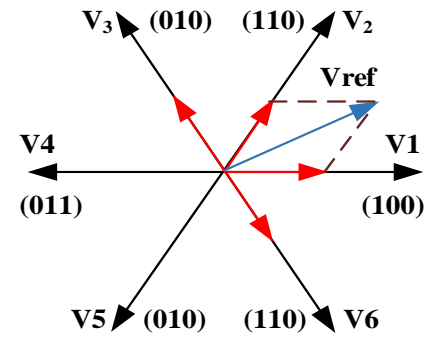

Fig 8. Space voltage vector schema in RCMV 4S-SVPWM.

The state $\mathrm{Sj}$ of the semiconductor switch can be set to get the 0 or 1 values, respectively with the sates of semiconductor switch conduct or dis-conduct. According to formula (1), Vcom can reach $\mathrm{Vd} / 6, \mathrm{Vd} / 3$, and $\mathrm{Vd} / 2$ values. The voltage vector states (000) and (111) will produce the maximum common mode voltage $(\mathrm{Vd} / 2)$; Active voltage vectors produce low common mode voltages $(\mathrm{Vd} / 6, \mathrm{Vd} / 3)$. In order to achieve the purpose reducing common mode voltage (RCMV), the PWM technique eliminates the (000) and (111) vector states in the tripping state. Therefore, we call the PWM technique called RCMV-PWM. Obviously, the RCMV PWM method has a state schema only containing positive voltage vectors.

The PWM technique reduces CMV can be implemented by the space vector modulation technique, called RCMV SVPWM. The vectors state zero will be replaced by the sum of the two positive vectors that are symmetric across the center of the hexagon, as shown in Fig. 8. For example, when considering the Vref vector in the first sector of a hex, the zero state vector can be replaced by one of the sums of the vectors (V100 + V011), (V110 + V010) and (V010 + V101).

In these three alterations, the combine two vectors (V101 + V010) are closest to the area that contains Vref vector, the RCMV SVPWM technique uses the four closest vectors to the Vref vector, Helps to reduce the common mode voltage. Because the SVPWM technique uses Four State vector (4S) with reduced common-mode voltage, we call this the RCMV 4S SVPWM.

2) RCMV 4S-CBPWM technique: Fig. 5 describes the principle of implementing CBPWM for 6P_VSI. The PWM control principle reduces the independent common mode voltage will be illustrated for the VSI I (Fig. 6). The RCMV CBPWM technique base on the way generates excitation pulse sj by comparing the three phase control voltage vdkA, vdkB and vdkC with the triangular carrier. The RCMV technical principle is based on two main characteristics:

- Determines the offset functions and control voltages;

_ Carrier technology

a) Determine the offset functions and control voltages

The three-phase control voltage vdkA, vdkB and vdkC can be deduced from the three-phase average voltage model ( Fig. 9 illustrates the average voltage model applied to a phase of VSI). We have the output voltage of VSI are: vA0, vB0, vC0:

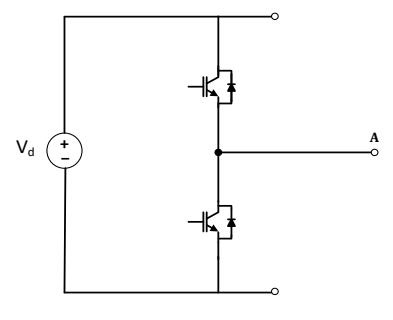

a)

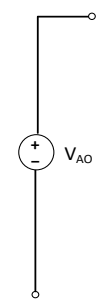

b)

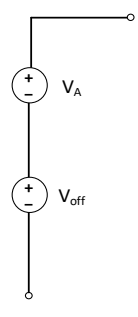

c)
Fig 9. The average voltage model applied to one phase of VSI (VA=VrefA, Voff= $=$ off*Vd).

$V_{A 0}=v_{d k A} V_{d}=V_{\text {refA }}+V_{c o m}+\frac{V_{d}}{2}$

$V_{B 0}=v_{d k B} V_{d}=V_{\text {refB }}+V_{\text {com }}+\frac{V_{d}}{2}$

$V_{C 0}=v_{d k C} V_{d}=V_{\text {refC }}+V_{c o m}+\frac{V_{d}}{2}$

The offset function in the average voltage model can be determined by the formula:

$v_{\text {off }}=\frac{v_{d k A}+v_{d k B}+v_{d k C}}{3}$

$v_{\text {off }} \cdot V_{d}-\frac{V_{d}}{2}=V_{\text {com }}$

The maximum, minimum, medium values of the threephase reference base voltage components are called Max, Min and Mid, these components required to be normalized according to the source Vd:

$$
\begin{aligned}
& \text { Max }=\frac{\operatorname{Maximum}\left(v_{\text {refA }}, v_{\text {refB }}, v_{\text {refC }}\right)}{V_{d}} \\
& \operatorname{Min}=\frac{\operatorname{Minimum}\left(v_{\text {refA }}, v_{\text {refB }}, v_{\text {refC }}\right)}{V_{d}} \\
& \text { Mid }=M_{\text {max }}-M_{\text {min }}
\end{aligned}
$$

The offset voltage can be inferred in the range between the voffmax and voffmin, it determined as follows:

$$
\begin{aligned}
& v_{\text {offMax }}=1-\text { Max } \\
& v_{\text {offMin }}=- \text { Min }
\end{aligned}
$$

Two maximum and minimum offset function values correspond to the average Vcom values as follows:

$$
\begin{aligned}
& V_{\text {comMax }}=(0.5-M a x) V_{d} \\
& V_{\text {comMin }}=(-0.5-M i n) V_{d}
\end{aligned}
$$

Max and Min are the maximum and minimum values of the three-phase control voltages. This Vcom indicates limits of instantaneous Vcom may occur at the working point of 3P_VSI. 
3) The conditions set up the offset function to reduced Vcom: In order, states string ensure limit Vcom as shown in Fig. 10, it is necessary to set up the constraint conditions of the offset function (22). Besides the general limitations of carrier technology (23), (24); The offset function needs to be more strictly limited under the condition that it generates the state order in Fig. 10. Calling these limits are eoMin and eoMax, which correspond to common mode ecomMin and ecomMax. We have:

$$
\begin{aligned}
& v_{d k M a x}+v_{d k M i d}>1 \\
& v_{d k M i d}+v_{d k M i n}<1
\end{aligned}
$$

where:

$$
\begin{aligned}
& v_{d k M a x}=\operatorname{Max}\left(v_{d k A}, v_{d k B}, v_{d k C}\right) \\
& v_{d k M i n}=\operatorname{Min}\left(v_{d k A}, v_{d k B}, v_{d k C}\right) \\
& v_{d k M i d}=v_{d k A}+v_{d k B}+v_{d k C}-v_{d k M a x}-v_{d k M i n}
\end{aligned}
$$

The ecomMin and ecomMax values are the determine functions that depend on the working position of the Vref space vector. ecomMin and ecomMax are related to the common mode extremes of CBPWM (28), (29) as follows:

$v_{\text {comMin }} \leq e_{\text {comMin }} \leq v_{\text {com }} \leq e_{\text {comMax }} \leq v_{\text {comMax }}$

Similar, we also can set-up relationship between the control functions for 3P_VSI II.

To perform the state sequences (101), (100), (110), (010) in the sampling cycle Ts, it is necessary to establish the difference between the carriers of the phases. For example, in the first sector, the carrier of phase $\mathrm{B}$ is shifted 180 degrees to the carriers of phase A and C, see Fig. 10.
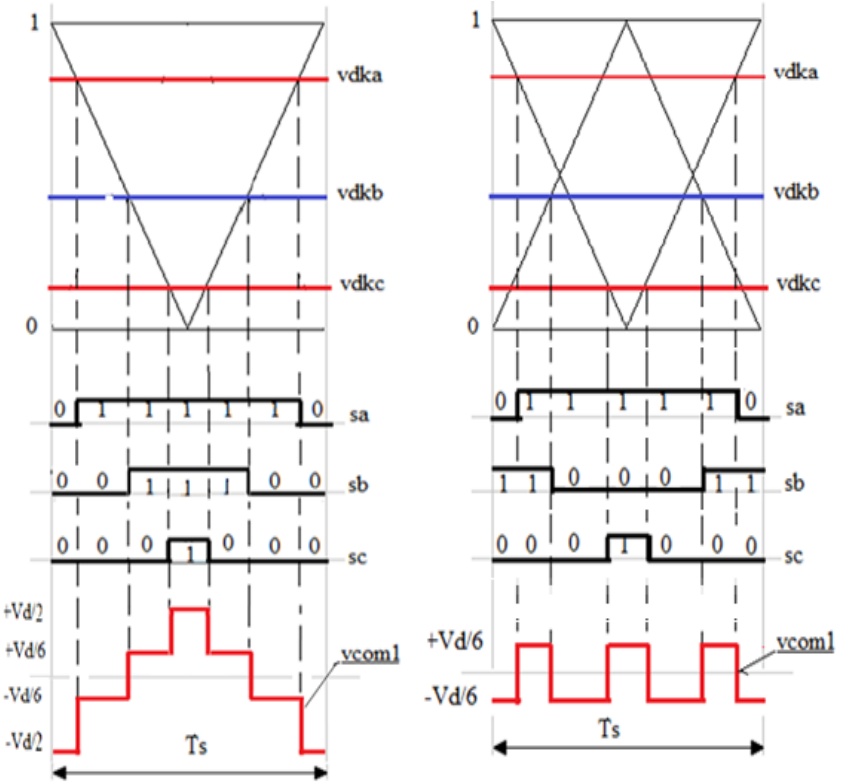

Fig 10. Excitation pulse scheme of RCMV 4S CBPWM technical for 3P_VSI.
The problem decides to the implement of 4S-CBPWM technique to reduce Vcom of the 6P_VSI is set up the average common mode voltage $V_{\text {comI }}, V_{\text {comII }}$ in formulas (16).

It can be said that to implement RCMV PWM reduces common mode voltage using four close state vectors (4SCBPWM). Common mode function values setup for two 3P_VSI I and II should meet the following conditions:

$$
\begin{aligned}
& e_{\text {comMinI }} \leq v_{\text {comI }} \leq e_{\text {comMaxI }} \\
& e_{\text {comMinII }} \leq v_{\text {comII }} \leq e_{\text {comMaxII }}
\end{aligned}
$$

Set the limits for common mode voltage of 6P_VSI when applying 4S-CBPWM:

$$
\begin{aligned}
& e_{\text {comMin }}=\frac{e_{\text {comMinI }}+e_{\text {comMinII }}}{2} \\
& e_{\text {comMax }}=\frac{e_{\text {comMaxI }}+e_{\text {comMaxII }}}{2}
\end{aligned}
$$

CMV of the 6P_VSI can be set up any value within the following limits:

$$
\mathrm{e}_{\text {comMin }} \leq \mathrm{v}_{\text {com }} \leq \mathrm{e}_{\text {comMax }}
$$

The proposed method satisfies if the common mode voltage value CMV satisfies (40) to implement the RCMV CBPWM technique. The values will need to be determined to implement the PWM technique for the VSI I and II.

\section{Proposal RCMV CBPWM Techniques}

1) RCMV CBPWM technique with average common mode voltage VcomMid: All common mode function values are set up individually and they allow reducing $V_{\text {com. }}$ This paper introduces two proposals of the choice of common mode function and its effects on the quality of six phase drive systems.

$$
\begin{aligned}
& \operatorname{Max}_{I}=\frac{\operatorname{Maximum}\left(v_{\text {refa }}, v_{\text {refb }}, v_{\text {refc }}\right)}{V_{d}} \\
& \operatorname{Min}_{I}=\frac{\operatorname{Minimum}\left(v_{\text {refa }}, v_{\text {refb }}, v_{\text {refc }}\right)}{V_{d}} \\
& \operatorname{Mid}_{I}=-\operatorname{Max}_{I}-\operatorname{Min}_{I}
\end{aligned}
$$

Similarly, for VSI II, we have:

$$
\begin{aligned}
& \operatorname{Max}_{I I}=\frac{\operatorname{Maximum}\left(v_{\text {refA }}, v_{\text {refB }}, v_{\text {refC }}\right)}{V_{d}} \\
& \operatorname{Min}_{I I}=\frac{\operatorname{Minimum}\left(v_{\text {refA }}, v_{\text {refB }}, v_{\text {refC }}\right)}{V_{d}} \\
& \operatorname{Mid}_{I I}=-\operatorname{Max}_{I I}-\operatorname{Min}_{I I}
\end{aligned}
$$

The common mode function for two VSI I and II performs to reduce common mode voltage by the formula: 
$v_{\text {comI }}=v_{\text {comMidI }}=\operatorname{Mid}_{I} \cdot \frac{V_{d}}{2}$

$v_{\text {comII }}=v_{\text {comMidII }}=\operatorname{Mid}_{I I} \cdot \frac{V_{d}}{2}$

Average value of common mode voltage of 6P_VSI:

$v_{\text {com }}=v_{\text {comMid }}=\left(\operatorname{Mid}_{I}+\operatorname{Mid}_{I I}\right) \cdot \frac{V_{d}}{4}$

It can be seen that the functions (47), (48), (49) satisfy conditions (36), (37) and (40), and the CBPWM technique with generating impact time of two farther vectors are the same. Two further vectors have effect as two vectors zero; therefore, harmonics will be less distorted. The relationship between $V_{\text {commax }}, V_{\text {commin }}$ and $V_{\text {commid }}$ is described in Fig. 11(a), (b). The 6P_VSI use the RCMV PWM technique with $V_{\text {commid }}$ always contains the average third harmonic mode common component with increasing magnitude according to the modulation index.

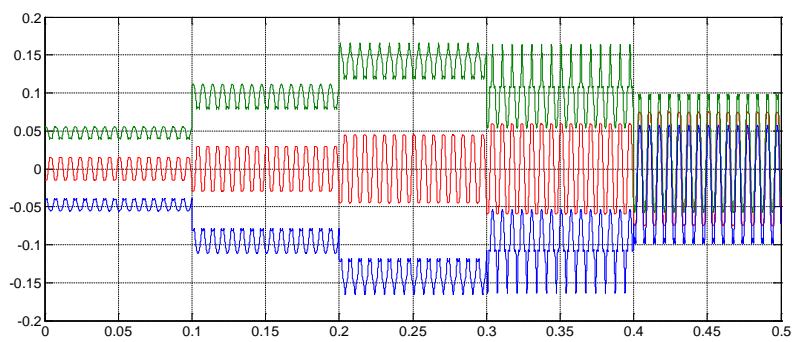

(a)

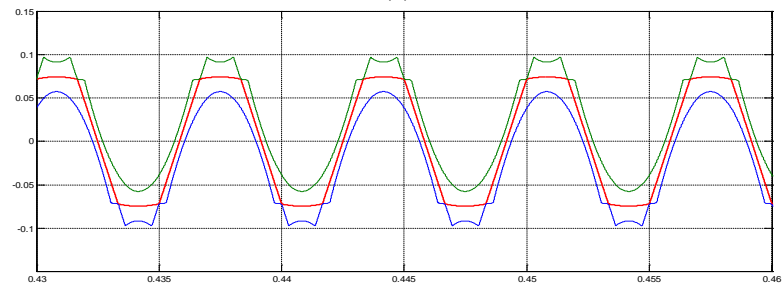

(b)

Fig 11. (a):Correlations diagram the average values of common mode voltage $e_{\text {comMax }}$ (green), VcomMid (red) and $e_{\text {comMin }}$ (blue) when changing modulation index $\mathrm{m}=0.2 ; 0.4 ; 0.6 ; 0.8$ and 1 . (b):Correlations diagram the average values of common mode voltage $e_{\text {commax }}$ (green), VcomMid (red) and $e_{\text {comMin }}$ (blue) during $\mathrm{m}=1$.

In formula (47), (48 (49) the Mid common mode voltage function is proportional to load phase voltage and is between the largest and smallest phase. Vm be called the amplitude of the load phase, the amplitude of the vcom varies depending on the magnitude of the load voltage and this voltage will greater when larger load voltage, as explained below:

$V_{\text {comMid }}=V_{m} \sin \left(30^{\circ}\right)=0.5 V_{m}$

The peak amplitude of the average common mode voltage is equal to half the amplitude of the base component of the output voltage. Therefore, as the load voltage increases, this method will make increase the triple harmonic of the common mode voltage component for the drive system.

Fig. 12 describes FFT analysis of the triple harmonic of VcomMid for $\mathrm{m}=0.4$.

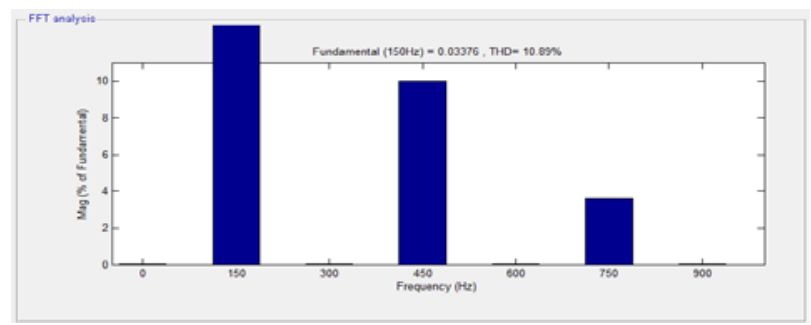

Fig 12. Correlations diagram the average values of common mode voltage $e_{\text {comMax }}$ (green), $V_{\text {comMid }}\left(\right.$ red) and $e_{\text {comMin }}$ (blue) when changing modulation index $\mathrm{m}=0.2 ; 0.4 ; 0.6 ; 0.8$ and 1 .

2) $4 S-C B P W M$ technique with the minimum common mode voltage $V_{\text {comopt }}$ : Recent, some published results showed that the existence of the triple harmonic component of Vcom would cause a high voltage stress on the motor particular when the inverter connected to the motor with a relatively long cable [14]. Therefore, in order to limit the triple harmonic component of CMV, we can choose the optimal and minimum common mode voltage in the equation (22) as follows:

$$
V_{\text {comOpt }}=\operatorname{Min}\left(V_{\text {com }}\right)
$$

In the range can control SIN PWM technique, mean the average value $V_{\text {com }}=0$. Thus, the output voltages don't contain the common mode triple harmonic component. Outside of this range, the $V_{\text {com }}$ values are chosen minimum from (22), (23) and (24). Detail, we will define the voltage $\mathbf{V}_{\text {comopt }}$ as the case of CBPWM having the function $V_{\text {com }}$ reach the least absolute value. Obviously, the special case of the CBPWM technique with low m modulation index is the SIN PWM technique. We have $v_{\text {comI }}=v_{\text {comII }}=0$. In the larger modulation index area, For example, when controlling VSI I independently with modulation index $\mathrm{m}=1$ conditions $e_{\text {comMinI }} \leq v_{\text {comI }}=0 \leq e_{\text {comMaxI }}$ cannot occur. Similarly, apply to VSI II.

The optimum mode common mode function has minimal common mode value that can be set as follows:

$$
\mathrm{v}_{\text {comOpt }}=\left\{\begin{array}{ccc}
\mathrm{e}_{\text {comMin }} & \text { if } & \mathrm{e}_{\text {comMin }}>0 \\
\mathrm{e}_{\text {comMax }} & \text { if } & \mathrm{e}_{\text {comMax }}<0 \\
0 & \text { if } & \mathrm{e}_{\text {comMin }}<0<\mathrm{e}_{\text {comMax }}
\end{array}\right.
$$

It is easy to see that defining of CMV function according to two conditions of the (53) relation is easy to solve:

$$
\left.\begin{array}{l}
v_{\text {comI }}=e_{\text {comMinI }} \\
v_{\text {comII }}=e_{\text {comMinII }}
\end{array}\right\} \text { if } \quad v_{\text {comOpt }}=e_{\text {comMin }}
$$

And:

$\left.\begin{array}{l}v_{\text {comI }}=e_{\text {comMaxI }} \\ v_{\text {comII }}=e_{\text {comMaxII }}\end{array}\right\}$ if $\quad v_{\text {comOpt }}=e_{\text {comMax }}$ 


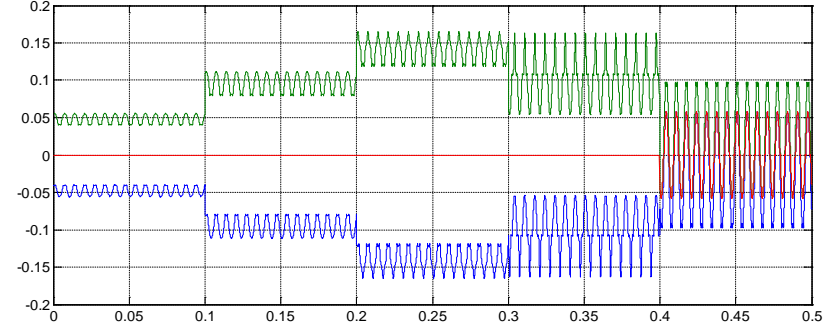

Fig 13. Correlations diagram the average values of common mode voltage $e_{\text {comMax }}$ (green), $V_{\text {comMid }}(\mathrm{red})$ and $e_{\text {comMin }}$ (blue) when changing modulation index $\mathrm{m}=0.2 ; 0.4 ; 0.6 ; 0.8$ and 1 .

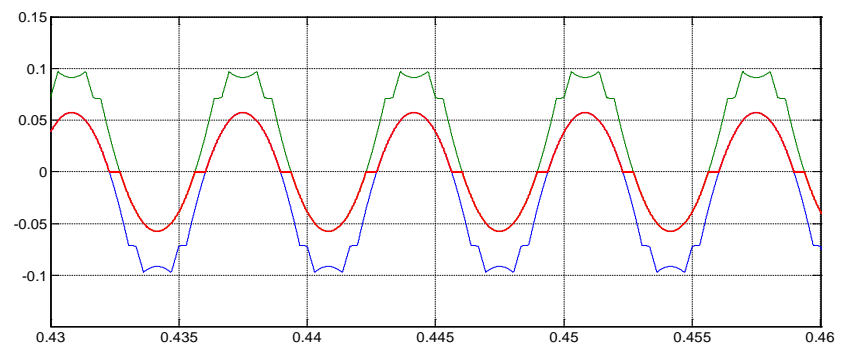

Fig 14. Correlations diagram the average values of common mode voltage $e_{\text {comMax }}$ (green), $V_{\text {comMid }}\left(\right.$ red) and $e_{\text {comMin }}$ (blue) during $\mathrm{m}=1$.

Find the common mode function for VSI I and II when the function $=0$ can be implemented by giving the parameter $\mathrm{k}, 0$ $<\mathrm{k}<1$, as follows:

$v_{\text {comI }}=(1-k) \cdot e_{\text {comMinI }}+k \cdot e_{\text {comMaxI }}$

$v_{\text {comII }}=(1-k) \cdot e_{\text {comMinII }}+k \cdot e_{\text {comMaxII }}$

The value of $\mathrm{k}$ is determined by the condition $\mathbf{v}_{\text {comopt }}=0$ :

$\mathrm{k}=-\frac{\mathrm{e}_{\text {comMin1 }}+\mathrm{e}_{\text {comMin2 }}}{\mathrm{e}_{\text {comMax1 }}+\mathrm{e}_{\text {comMax } 2}-\mathrm{e}_{\text {comMin1 }}-\mathrm{e}_{\text {comMin2 }}}$

Or short form:

$$
\mathrm{k}=-\frac{\mathrm{e}_{\text {comMin }}}{\mathrm{e}_{\text {comMax }}-\mathrm{e}_{\text {comMin }}}
$$

The correlation between the maximum and minimum common mode voltages with common mode voltage VcomOpt is shown in Fig. 13 and Fig. 14.

The 6P_VSI uses the RCMV PWM technique using VcomOpt to reach the minimum average common mode value. When the modulation index $\mathrm{m}<0.866$, VcomOpt $=0$. It can be said that the RCMV PWM technique with VcomOpt acts as the SIN PWM technique extends to the maximum voltage value of the VSI, where the modulation index is equal to 1

3) RCMV POD-CBPWM technique: The POD_CBPWM technique for 6P_VSI can be defined as a conventional SIN PD-CBPWM technique. The difference is that the CBPWM block in Fig. 4, when applied to VSI II, will use a 180 degree phase shift carrier compared to the carrier used for VSI I CBPWM block. As described in Fig. 4, the Vcom function is determined by zero $($ Vcom $=0)$.

\section{Simulation Results AND Discussion}

Simulation analysis has been carried out by MATLAB/ Simulink to verify the proposed methods. Comparisons with the conventional SIN CBPW technique are also presented in this section.

1) The conventional SIN CBPW technique: SIN PD CBPWM technique uses the same phase carrier for both 3P_VSI I and II. The results of Fig. 15 and 16 show that the Vcom common mode voltage changes to the highest peak values $\pm \mathrm{Vd} / 2$. The limited control range of the SIN CBPWM technique is the largest modulation index $\mathrm{m}=0.866$.

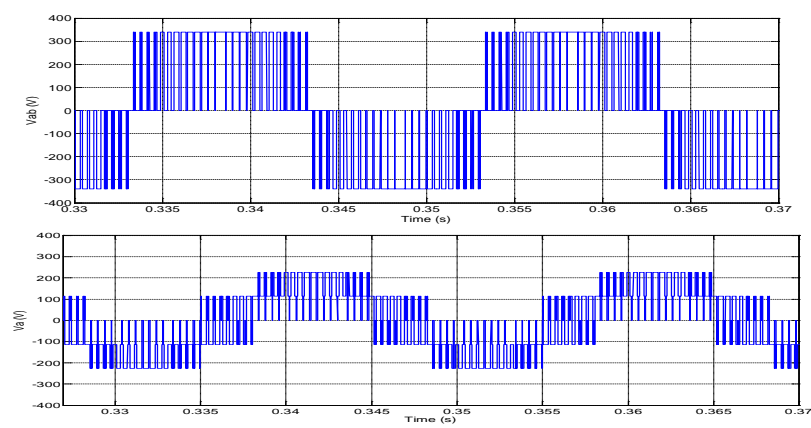

Fig 15. SIN PD PWM technique, $\mathrm{m}=0.8$ - Diagram of the line voltage and phase voltage.

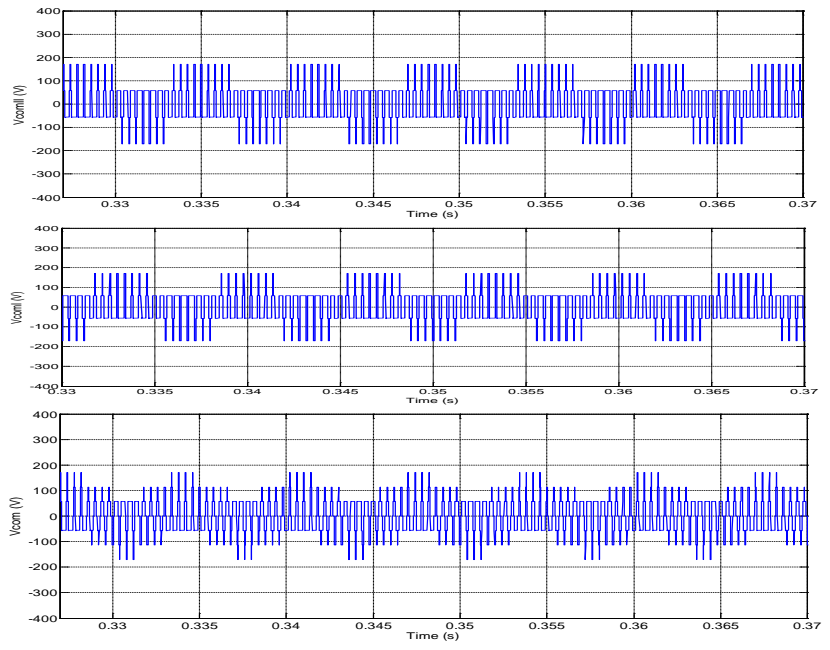

Fig 16. SIN PD PWM technique, $\mathrm{m}=0.8$ - Diagram of common mode

$$
\text { voltage } v_{\text {comI }}, v_{\text {comII }} \text { and } v_{\text {com of } 6 P_{-} \text {VSI. }}
$$

2) SIN POD CBPWM technique: SIN POD CBPWM technique utilizes the carriers for VSI II is shifted phase 180 degrees to the carriers for VSI I. The results show that, in Fig. 17 and 18, the SIN POD CBPWM instantaneous-mode voltage value decreases within the limits $V_{\text {com(peak })= \pm} V_{d} / 6$, although the common mode voltage components have peak values $V_{\text {com(peak })={ }_{ \pm}} V_{d} / 2$. It is easy to see that, because the voltage of each 3P_VSI is controlled PWM independently, the output voltage quality of the SIN POD CBPWM technique is also equal to the harmonic quality of the SIN PD CBPWM technique. The SIN POD CBPWM technique has a control range limited to the largest modulation index $\mathrm{m}=0.866$. 

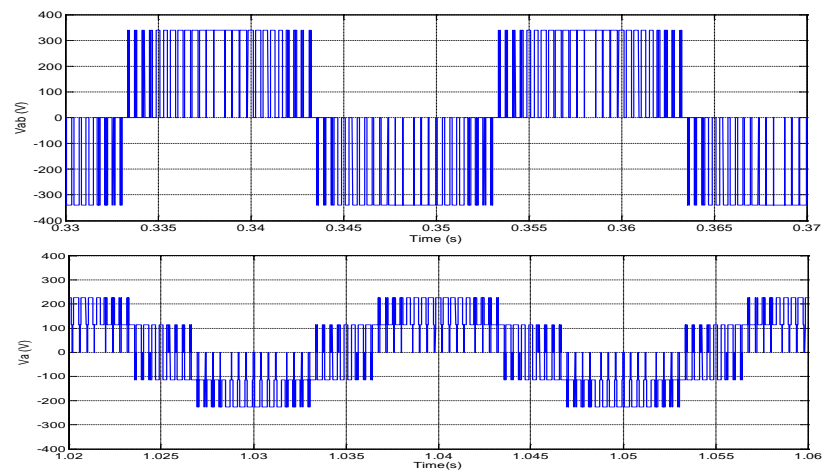

Fig 17. SIN POD PWM technique, $\mathrm{m}=0.8$ - Diagram of the line voltage and phase voltage, $\mathrm{m}=0.8$.
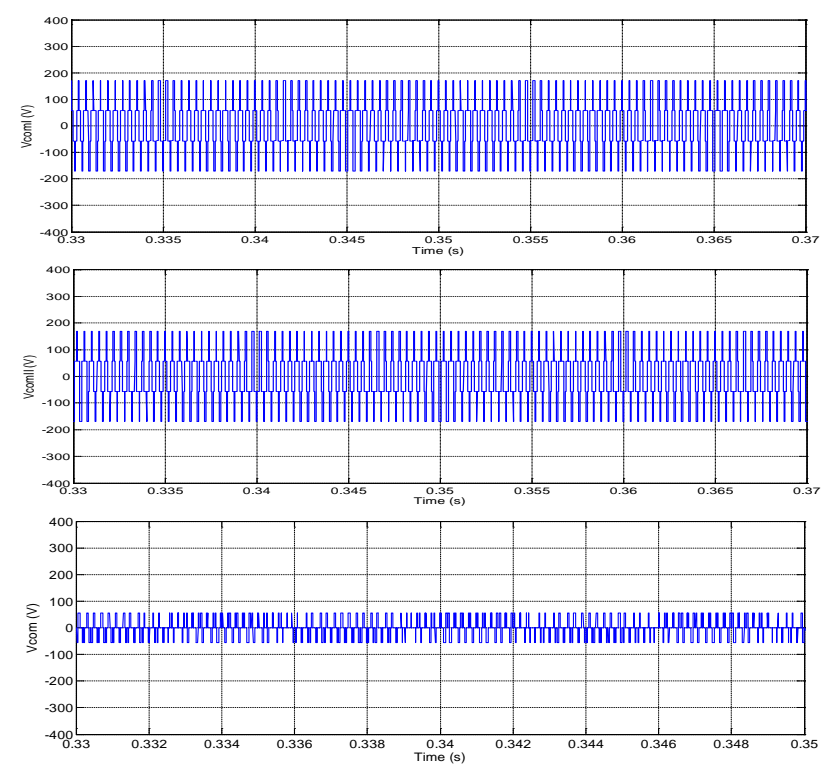

Fig 18. SIN POD PWM technique, $m=0.8$ - Diagram of common mode

$$
\text { voltage } v_{\text {comI }}, v_{\text {comII }} \text { and } v_{\text {com of } 6 \text { P_VSI. }}
$$

To extend RCMV PWM to $\mathrm{m}=1$, it is possible to use (45) to create the VcomOptI, VcomOptII optimizer for each of VSI I, II. Vcom voltage of 6P_VSI (Fig. 13a) will be larger than the coordinate control case (Fig. 13b).

3) RCMV 4S-PWM technique with VcomMid: The results of Fig. 19 and 20 show that the instantaneous common-mode voltage value of the RCMV 4S-CBPWM technique decreased within the limits $V_{\text {com(peak })= \pm} V_{d} / 6$. Unlike the RCMV POD CBPWM, this method simultaneously controls the common mode voltage components within the above limits $V_{\text {comIIII }}$ $($ peak $)= \pm V_{d} / 6$. The voltage of each 3P_VSI is controlled PWM independently to $\mathrm{m}=1$.

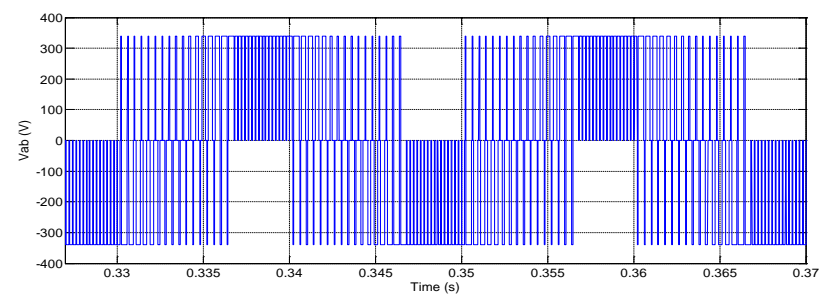

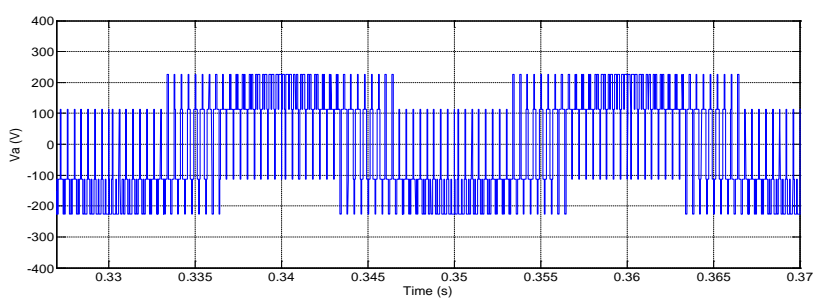

Fig 19. RCMV 4S-PWM technique with VcomMid, $m=0.8$ - Diagram of the line voltage and phase voltage, $\mathrm{m}=0.8$.
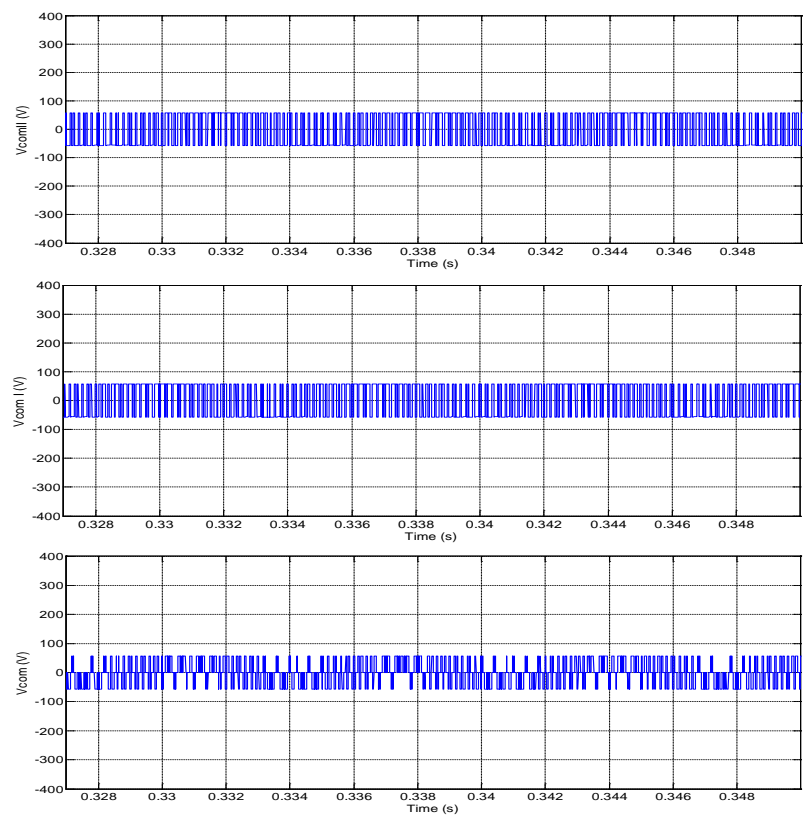

Fig 20. RCMV 4S-PWM technique with VcomMid, $\mathrm{m}=0.8-$ Diagram of common mode voltage $v_{\text {comI }}, v_{\text {comII }}$ and $v_{\text {com of } 6 \mathrm{P} \_V S I}$

4) $4 S-P W M$ technique with VcomOpt: The results in Fig. 21 and 22 show that the instantaneous common-mode voltage value of the RCMV 4S-PWM technique with VcomOpt decreases within the limits, while the common mode voltage component also decreases within the above limit, $v_{\text {comI II }}($ peak $)= \pm V_{d} / 6$. The voltage of each 3P_VSI is controlled independently of the PWM to the limit of $\mathrm{m}=0.866$. In range $(\mathrm{m}>0.866)$ from the modulation index $\mathrm{m}=0.866$ to 1 , the offset voltages of the two VSI I, II will be constrained under the extreme condition of the $\mathrm{V}_{\text {com }}$ function.

From the principle of the RCMV methods performed and the load current diagram obtained through Simulink, it can be observed that the RCMV POD CBPWM technique will give better output quality than the other two methods. The RCMV method 4S CBPWM has an operational range up to modulation index $m=1$. In that, due to the symmetry time distribution of the two far vectors, the PWM method with $\mathrm{V}_{\text {comMid }}$ will be of better quality. Evaluation of the average common mode voltage, the RCMV-4S CBPWM method will provide a minimum common mode voltage, which can help to limit the common mode amplitude when the drive system is connected to SPIM with a long cable. 


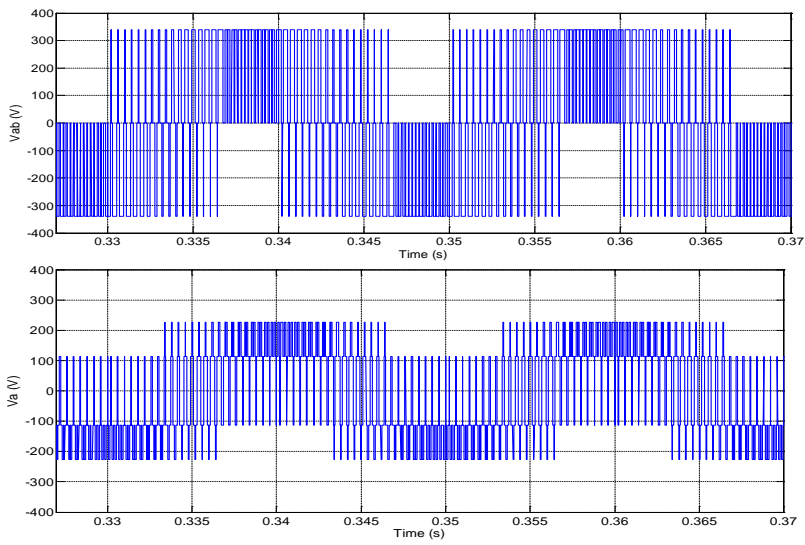

Fig 21. RCMV 4S-PWM technique with $\mathrm{V}_{\text {comopt }}, \mathrm{m}=0.8$ - Diagram of the line voltage and phase voltage, $\mathrm{m}=0.8$.
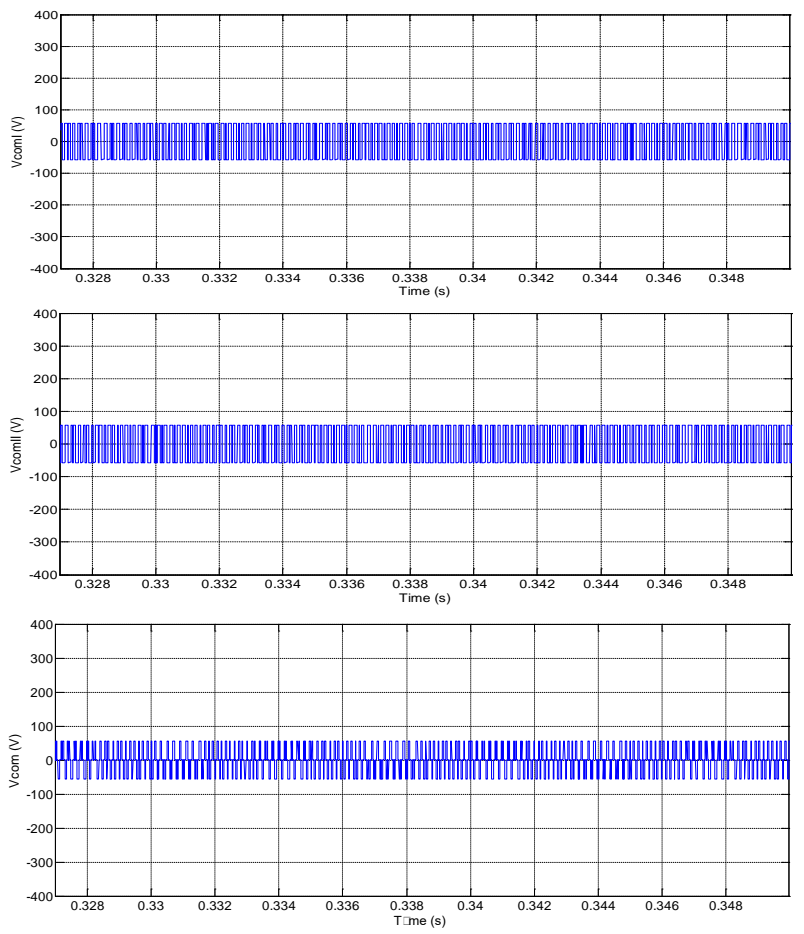

Fig 22. RCMV 4S-PWM technique with VcomOpt, $\mathrm{m}=0.8$ - Diagram of common mode voltage $\mathrm{V}_{\text {comI }}, \mathrm{V}_{\text {comII }}$ and $\mathrm{V}_{\text {com }}$ of 6P_VSI.

\section{EXPERIMENT RESULTS}

The characteristics of the proposal CBPWM methods were investigated experimentally; the experimental set-up is illustrated in Fig. 23. The proposal RCMV technologies, described in Section 4, is implemented on TMS320F28335 digital signal processor (DSP), which is used to control sixphase VSI of SPIM drive with the parameters of SPIM: 1HP, phase voltage $240 \mathrm{~V}, 50 \mathrm{~Hz}, 4$ pole , $1450 \mathrm{rpm}$. Rs $=10.1 \Omega$, $\mathrm{Rr}=9.8546 \Omega, \mathrm{Ls}=0.833457 \mathrm{H}, \mathrm{Lr}=0.830811 \mathrm{H}, \mathrm{Lm}=$ $0.783106 \mathrm{H}, \mathrm{Ji}=0.0088 \mathrm{~kg} . \mathrm{m} 2$.

The theoretical analysis and simulation results have been verified with experiments carried out the SPIM drive with the same ratings, parameters, and operating conditions as those of the simulations. As discussed and simulink in part 3 and part 4, the conventional Sin_PD PWM technique has been implemented to compare to three proposal methods: RCMV_POD_CBPWM technique, RCMV-4S CBPWM techniques with $\mathrm{V}_{\text {mid }}$ and ${ }_{\text {vopt }}$.

Fig. 24 and 25 are the experimental results corresponding to the simulation waveforms of Fig. 15 and 16, respectively; similar, Fig. 26 and 27 are the experimental results corresponding to the simulation waveforms of Fig. 17 and 18, respectively; Fig. 28 and 29 are the experimental results corresponding to the simulation waveforms of Figs. 19 and 20, respectively, Fig. 30 and 31 are the experimental results corresponding to the simulation waveforms of Fig. 21 and 22, respectively. There is a strong correlation between the waveforms of experiments and simulations. In the experimental waveforms, slightly larger ripple than the simulation waveforms is observed.

The CMV comparison indicates that both RCMV-4S CBPWM techniques with $\mathrm{V}_{\text {mid }}$ and $\mathrm{V}_{\text {opt }}$ have low CMV components (Vcom I, VcomII) compared to other methods. With conventional SinPD-PWM and RCMV_POD_CBPWM technique, the peak component $\mathrm{CMV}$ are $\pm \overline{\mathrm{V}} \mathrm{d} / 2$, RCMV_4S Vmid_PWM, RCMV_4S_Vopt_PWM methods are \pm Vd/6 reduce approximately $77 \%$ to the conventional methods. However, general CMV(Vcom) of the RCMV_POD_CBPWM technique is equal the general $\mathrm{CMV}$ (Vcom) of RCMV_4S_Vmid_PWM and RCMV_4S_V methods by $\pm \mathrm{Vd} / 6$ reduce approximately $77 \%$ to the conventional methods.

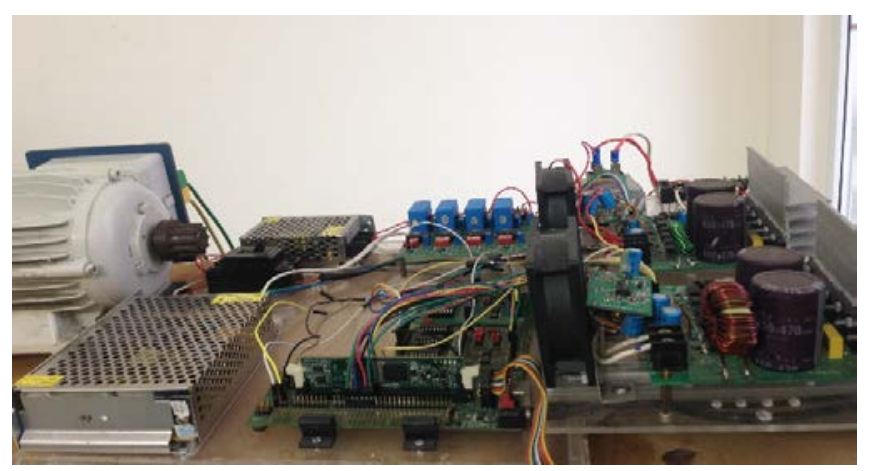

Fig 23. Six-phase voltage source inverter.

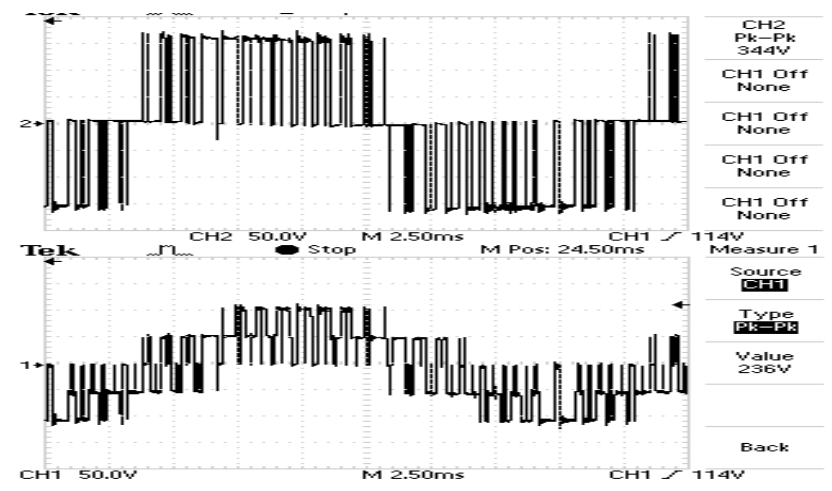

Fig 24. SIN PD PWM technique, $\mathrm{m}=0.8$ - Diagram of the line voltage and phase voltage. 


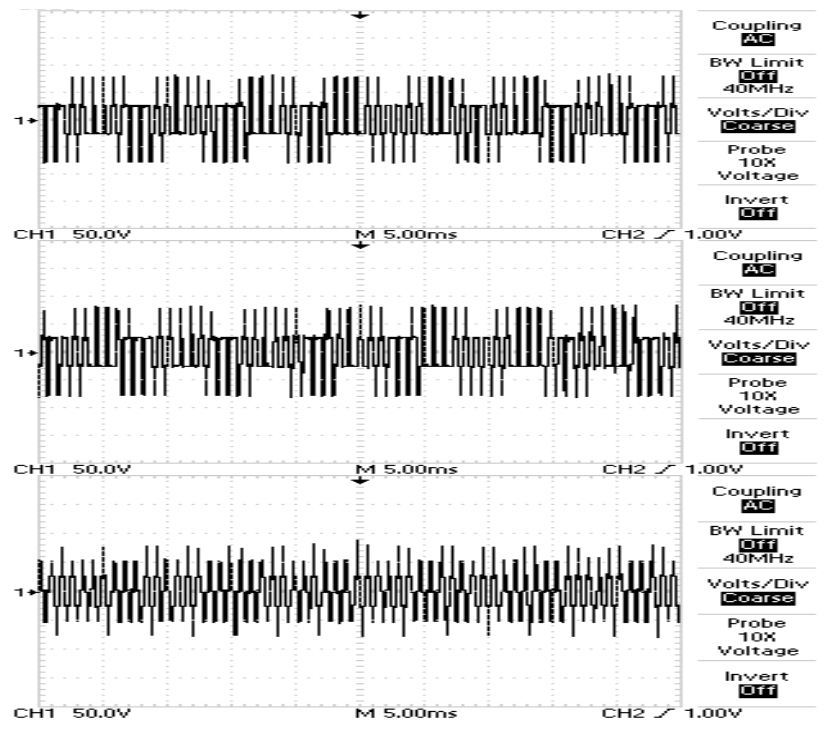

Fig 25. SIN PD PWM technique, $\mathrm{m}=0.8$ - Diagram of common mode voltage $\mathrm{V}_{\text {comI }}, \mathrm{V}_{\text {comII }}$ and $\mathrm{V}_{\text {com }}$ of $6 \mathrm{P}_{-} \mathrm{VSI}$.

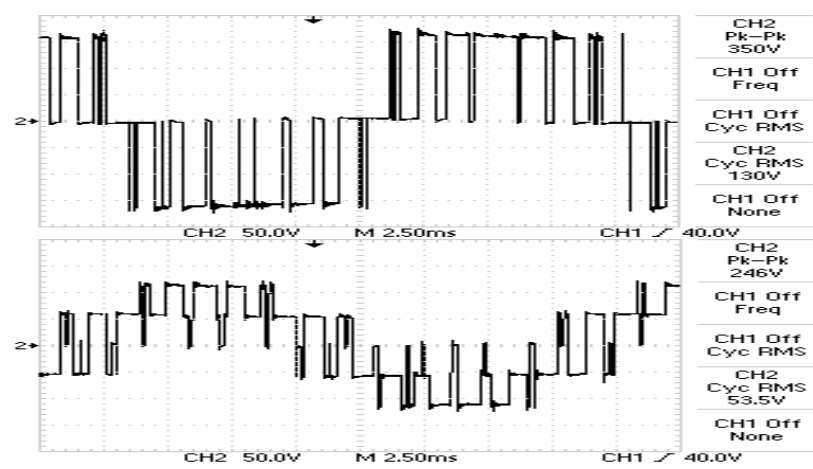

Fig 26. SIN POD PWM technique, $\mathrm{m}=0.8$ - Diagram of the line voltage and phase voltage.

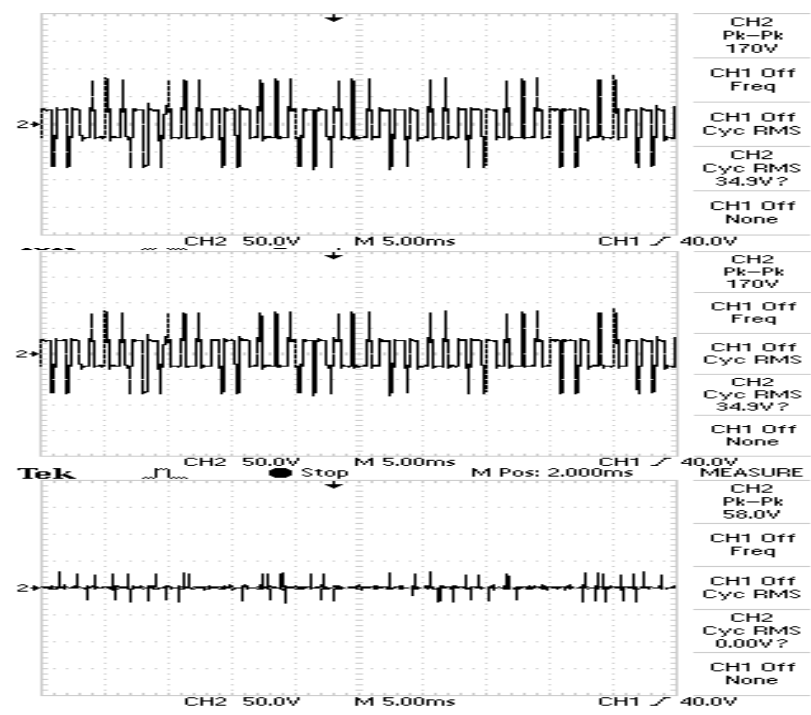

Fig 27. SIN POD PWM technique, $m=0.8$ - Diagram of common mode voltage $\mathrm{V}_{\text {comI }}, \mathrm{V}_{\text {comII }}$ and $\mathrm{V}_{\text {com }}$ of 6P_VSI.

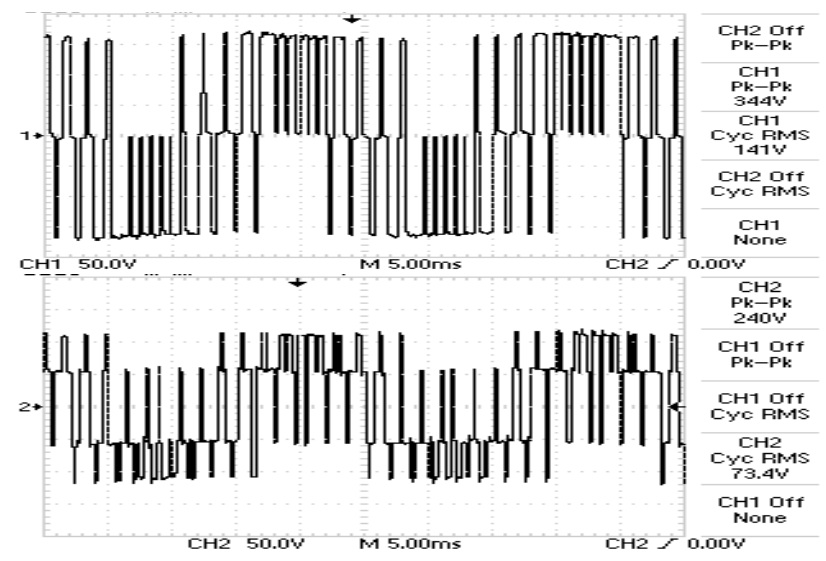

Fig 28. RCMV 4S-PWM technique with Vcommid, $m=0.8$ - Diagram of the line voltage and phase voltage.

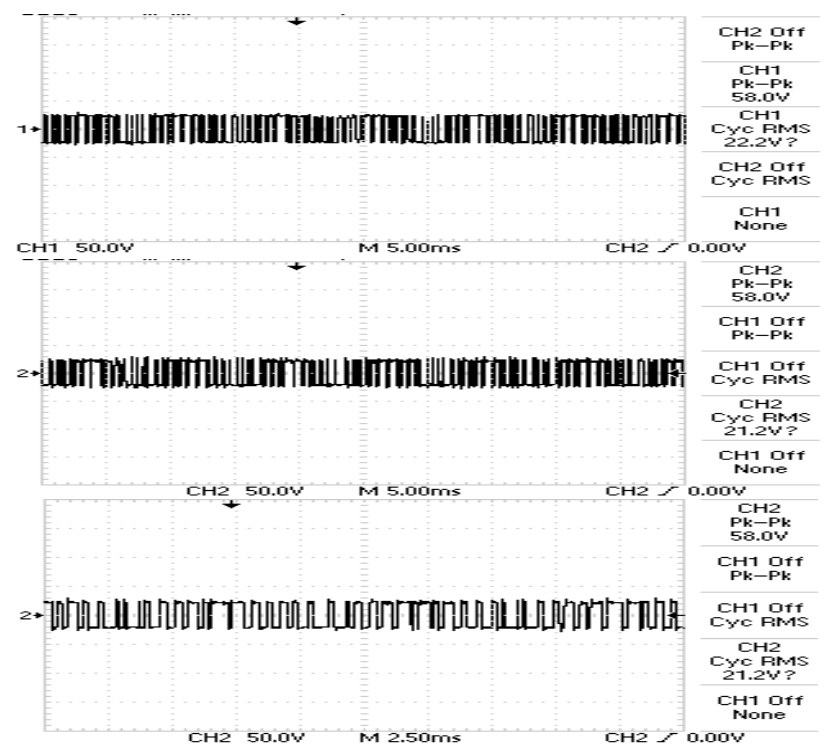

Fig 29. RCMV 4S-PWM technique with Vcommid, $m=0.8$ - Diagram of common mode voltage $v_{\text {comI }}, v_{\text {comII }}$ and $v_{\text {com of } 6 \text { P_VSI. }}$

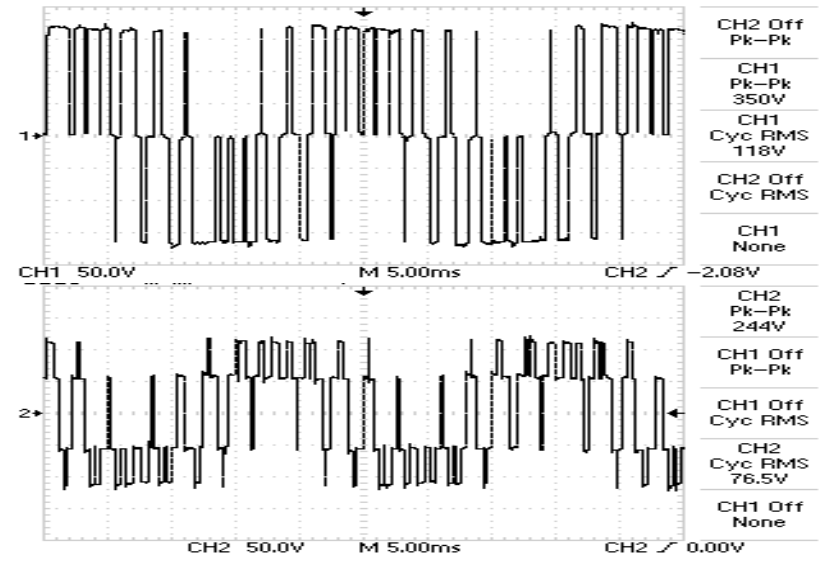

Fig 30. RCMV 4S-PWM technique with Vcommid, $\mathrm{m}=0$.8- Diagram of the line voltage and phase voltage. 


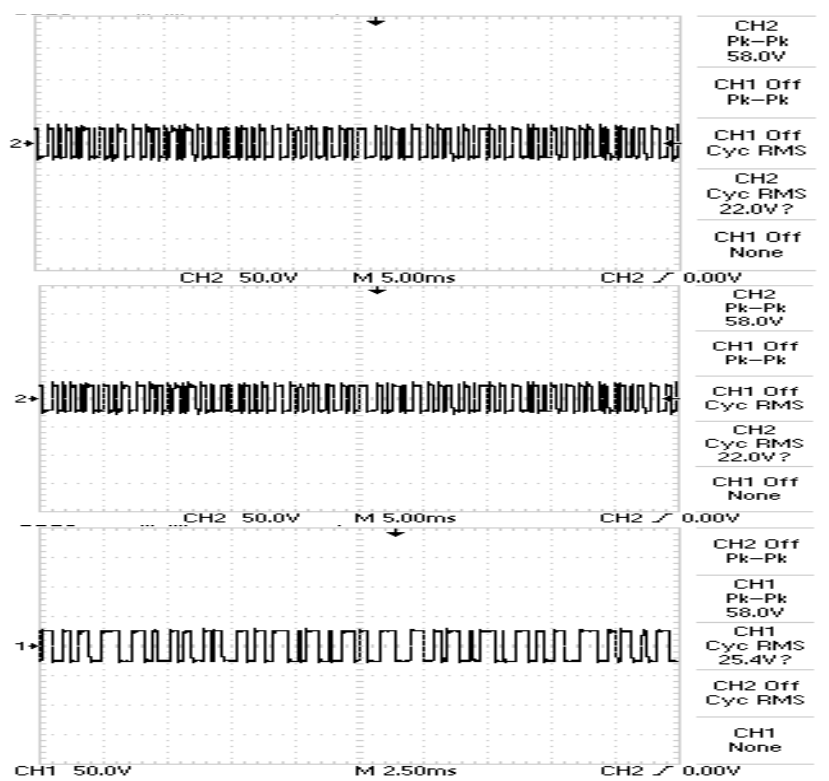

Fig 31. RCMV 4S-PWM technique with VcomOpt, $m=0.8$ - Diagram of common mode voltage $\mathrm{V}_{\text {comI }}, \mathrm{V}_{\text {comII }}$ and $\mathrm{V}_{\text {com }}$ of 6P_VSI.

\section{CONCLUSION}

This paper presents a novel CBPWM technique to reduce CMV for SPIM VSI. These proposal schemes are implemented simply, require low calculation effort. The average CMV control range is also explained. CBPWM techniques reduce common mode voltage in $\mathrm{Vd} / 6$ range. The RCMV POD CBPWM method is very simply implemented. This proposal helps to reduce the common mode voltage and achieves high output voltage quality. However, this scheme has the range of modulation index $\mathrm{m}$ only up to $\mathrm{m}=0866$. RCMV 4S-CBPWM techniques are capable to perform in range entire of the hexagonal voltage vector, mean this proposal schema has modulation index $\mathrm{m}$ up to $\mathrm{m}=1$. The calculations show that the responses of the CBPWM technique using VcomMid function produces better output harmonics; while the method using VcomOpt function produce the smallest triple harmonic component or by zero. Because of using the two further vectors, the 4S-CBPWM methods have the responses of output harmonics not good by using the CBPWM POD technique. The theoretical analysis and simulation results have been verified with experiments carry out SPIM drive with the same ratings, parameters, and operating conditions as those of the simulations. In the experiments, the conventional Sin_PD PWM has been implemented. As discussed in Section 3 to compare with three proposal methods Sin_POD PWM, RCMV_4SVmid_PWM, RCMV_4SVmid_PWM technique. The CMV comparison indicates that both RCMV_4S_Vmid_PWM and RCMV_4S_VOpt_PWM technique have low CMV components (Vcom I, VcomII) compared to other methods. With Sin PD-PWM and, the peak component CMV are Vd/2, RCMV_4S_Vmid_PWM,
RCMV_4S_Vmid_PWM methods are Vd/6 reduce approximately $77 \%$ to the conventional methods. However, general CMV(Vcom) of Sin POD-PWM method are equal the general CMV(Vcom) of RCMV_4S_Vmid_PWM and RCMV_4S_Vmid_PWM methods by Vd/6 reduce approximately $77 \%$ to the conventional methods. As analysed, the use of the six phase induction motor drives are recommended for the high power applications, where the use of multi_level 6P_VSI is considered replacing the two level 6P_VSI in some cases require high voltage. Therefore, it will be interesting if an investigation is carried out to study continue to develop and improve the proposed techniques in this paper to reduce common mode voltage for the six phase drives using the multi_level 6P_VSI in future.

\section{REFERENCES}

[1] M.B.R. Corra, C.B. Jacobina, C.R. da Silva, A.N. Lima, E. R. C. da Silva,"Six-phase AC drive system with reduced common-mode voltage", IEEE International Electric Machines and Drives Conference, pp.1852-1858, 15 July 2003.

[2] Drazen Dujic, Atif Iqbal, Emil Levi "A Space Vector PWM Technique for Symmetrical Six-Phase Voltage Source Inverters”, EPE Journal, vol. 17, no. 1, pp-24-32, March 2007.

[3] R. Kianinezhad, B. Nahid-Mobarakeh, L. Baghli, F. Betin, G.A. Capolino, Modeling and Control of Six-Phase Symmetrical Induction Machine Under Fault Condition Due to Open Phases, IEEE Trans. Ind. Elec., vol. 55, no. 5, pp. 1966-1977, May 2008.

[4] R. Kianinezhad1, R. Alcharea2, B. Nahid3, F. Betin2, Analysis and Evaluation of DTC and FOC in Open Phase Fault Operation of SixPhase Induction Machines G.-A. Capolino2, 978-1-4244-1633-2/08/.00 (C)2008 IEEE

[5] R. Bojoi, A. Tenconi, F. Profumo, G. Griva, D. Martinello, “Complete Analysis and comparative study of digital modulation techniques for dual three phase AC motor Drives”, pp. 851-857, IEEE PESC 2002.

[6] F. Wang, "Motor shaft voltages and bearing currents and their reduction in multilevel medium-voltage PWM voltage-source-inverter drive applications,” IEEE Trans. Ind. Appl., vol. 36, no. 5, pp. 1336 -1341, Sep./Oct. 2000.

[7] R. Naik, T. A. Nondahl, M. Cacciato, A. Consoli, G. Scarcella, and A. Testa, "Reduction of common mode currents in PWM inverter motor drives” IEEE Trans. Ind. Appl., vol. 35, no. 2, pp. 469-476, Mar./Apr. 1999.

[8] G.Oriti, A.L. Julian, T. Lipo, An Inverter/Motor Drive with Common Mode Voltage Elimination, IEEE IAS Proceedings 1997.

[9] J. Huang and H. Shi, "Reducing the common-mode voltage through carrier peak position modulation in an SPWM three-phase inverter,"IEEE Trans. Power Electron., vol. 29, no. 9, pp. 4490-4495, Sep. 2014.

[10] M. H. Hedayati, A. B. Acharya, and V. John, "Common-mode filter design for PWM rectifier-based motor drives," IEEE Trans. Power Electron., vol. 28, no. 11, pp. 5364 - 537, Nov. 2013.

[11] H. Akagi and S. Tamura, "A passive EMI filter for eliminating both bearing current and ground leakage current from an inverter-driven motor," IEEE Trans. Power Electron., vol. 5, no. 5, pp. 1459-1469, Sep. 2006.

[12] Kai Tian, Jiacheng Wang, Bin Wu, Dewei Xu, Zhongyuan Cheng, Navid Reza Zargari, “A Virtual Space Vector Modulation Technique for the Reduction of Common -Mode Voltages in both Magnitude and Third-Order Component”, IEEE Transactions on Power Electronics, Vol. 31, No.1, Jan. 2016. 
[13] E. Un and A. M. Hava, "A near-state PWM method with reduced switching losses and reduced common-mode voltage for three-phase voltage source inverters,” IEEE Trans. Ind. Appl., vol. 45, no. 2, pp. 782-793, Mar./Apr. 2009.

[14] A. M. Hava and E. Un, "A high-performance PWM algorithm for common mode voltage reduction in three-phase voltage source inverters,” IEEE Trans. Power Electron., vol. 26, no. 7, pp.1998-2008, Jul. 2011.

[15] M. Pulirenti, G. Scarcella, G. Scelba, and M. Cacciato, "Space Vector Modulation technique for Common Mode Currents reduction in six phase AC drives” DIEES-UNIVERSITY OF CATANIA Viale A. Doria, 6 95125, Catania, Italy

[16] Rutian Wang, Xingjun Mu, Zhiqiang Wu, Lihui Zhu, Qiufeng Chen and Xue Wang; "Carrier-Based PWM Method to Reduce Common-Mode Voltage of Three-to-Five-Phase Indirect Matrix Converter" Hindawi Publishing Corporation Mathematical Problems in Engineering, Vol. 2016, Article ID 6086497, 10 pages.

\section{ACKNOWLEDGMENT}

This research funded by the National Foundation for Science and Technology Development (NAFOSTED). Project code: 103.01-2015.53

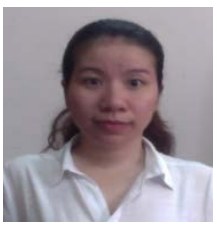

Ngoc Thuy Pham was born in Viet Nam, in 1976 She received the B.Sc degrees in Electrical Engineering from Thai Nguyen University of Technology (TNUT) in 1994, and the M.Sc from Ho Chi Minh City University of Technology ( HCMUT) in 2009. She worked from 2000 in the Faculty of Electrical Engineering, Industrial University of Ho Chi Minh City (IUH). Her current research interests include AC motor drives, active power filters, and PWM techniques for power converters. multiphase induction motor, sensorless control of multiphase induction motor drives.

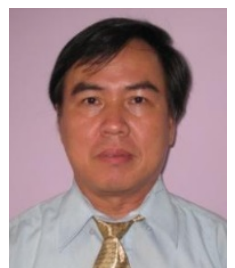

Nho Van Nguyen was born in Vietnam in 1964. He received his M.S. and Ph.D. degrees in Electrical Engineering from the University of West Bohemia, the Czech Republic in 1988 and 1991 respectively. Since 1992, he has been with the Department of Electrical and Electronics Engineering, Ho Chi Minh City University of Technology, Vietnam, where he is currently an Associate Professor. He was with KAIST as a Post-doc Fellow for six months in 2001 and a Visiting Professor for a year in 2003-2004. He was a visiting scholar at the Department of Electrical Engineering, University of Illinois at Urbana-Champaign for a month in 2009. His research interests include modeling and control of switching power supplies, AC motor drives, active power filters, and PWM techniques for power converters. He is a member of the Institute of Electrical and Electronics Engineers (IEEE). 